\title{
RODA DE CONVERSA: MITOS E VERDADES SOBRE O COLOSTRO
}

Tcharlyson de Freitas RIBEIRO*

Dioclécio de Sousa CIRILO*

Ana Paula Sá MENEZES**

*Acadêmicos do curso de Enfermagem da Faculdade Roraimense de Ensino Superior, Boa Vista, RR. E-mail: tcharlysonfr@gmail.com

** Mestre em Ensino de Ciências na Amazônia. Chefe da Divisão de Pesquisa do Museu Integrado de Roraima. Professora do curso de Enfermagem da Faculdade Roraimense de Ensino Superior, Boa Vista, RR, na disciplina de Educação para a Saúde. E-mail: ana-p_sa@ @otmail.com

Recebido em: 11/08/2015 - Aprovado em: 12/01/2016 - Disponibilizado em: 30/07/2016

\begin{abstract}
RESUMO
O leite materno é tão antigo quanto a humanidade. Por milênios, foi o único recurso para a alimentação de lactentes e, ainda hoje, aqueles que são privados dele, estão mais suscetíveis a terem alguns problemas relacionados aos elementos imunológicos presentes no leite materno que atuam como a primeira vacina após o nascimento da criança. O objetivo principal dessa pesquisa é desconstruir alguns mitos que muitas mães, em especial a da ESF estudada, sobre o colostro, em rodas de conversa durante as consultas de pré-natal no posto. A pesquisa foi do tipo pesquisa-ação e aprovada pelo MS via Plataforma Brasil, sob CAEE 38111714.5.0000.5301. Foram consideradas gestantes adultas na faixa etária de 19 a 45 anos, inclusive, primíparas e/ou multíparas. As técnicas aplicáveis foram: a observação participante, a história de vida e a aplicação de um questionário. As rodas de conversa aconteceram no horário das consultas do pré-natal. Verificou-se que as gestantes não conheciam ao certo o colostro. Muitas pensavam, inclusive, que era apenas um leite fraco que sai nas primeiras lactações, não acreditando que o colostro seja a primeira vacina para o RN. Em relação à roda de conversa, constatou-se que essa técnica foi bem recebida e aceita pelas mães. Conclui-se que o colostro é de essencial importância para o RN e deve ser passado a cada gestante sua real funcionalidade, mostrando cada fator benéfico que ocorre ao seu filho não só quando ele nasce e o tempo de lactação do colostro, mas também para toda uma vida, pois ele traz todos os benefícios que o neonato precisa.
\end{abstract}

PALAVRAS-CHAVE: Colostro. Importância do colostro. Amamentação. Roda de Conversa. Enfermagem.

\begin{abstract}
Breast milk is a product so old as humanity itself. For millennia, it was the only recourse for feeding infants and, even today, those who are deprived of it are more likely to have some problems related to immunological elements present in breast milk that act as the first vaccine after child birth. The main objective of this research is to deconstruct some myths that many mothers, in particular those present in the studied ESF, about colostrum, in conversation circles during prenatal consultations at health care Center. The employed method was action research and was approved by the Ministry of Health by Platform Brazil, under code CAEE 38111714.5.0000.5301. Adult women were considered in the age group 19-45 years, including, gilts and / or multiparous. The applicable techniques were: participant observation, life history and the application of a questionnaire. The conversation circles happened in the time of pre-natal consultations at UBS. It was found that pregnant women did not know for sure colostrum. Many thought even that was only a weak milk coming out in the first lactation, not believing that colostrum is the first vaccine for the newborn. Regarding the conversation circles, it was found that this technique was well received and accepted by the mothers. We conclude that the colostrum is of vital importance for the newborn and must be transmitted for every pregnant women their real functionality, showing each beneficial factor for child not only when he is born and the colostrum lactation time, but also for a lifetime because it brings all the benefits that the newborn needs.
\end{abstract}

KEYWORDS: Colostrum. Colostrum importance.Breastfeeding. Conversation circles. Nursing.

\section{INTRODUCÃO}

O colostro é uma secreção láctea, definida como o primeiro produto da lactação, sendo secretada antes do nascimento da criança até sétimo dia pós-parto, constituindo o leite que possui a maior quantidade de agentes anti- infeciosos, agindo no intestino do recémnascido. De acordo com Issler (2008, p. 275), "o colostro, possibilita a aquisição de componentes solúveis e celulares imunologicamente competentes complexos na proteção do recém-nascido contra inúmeras 
doenças". Particularmente, com um número muito grande de leucócitos e de imunoglobulinas fazendo a defesa metabólica, o colostro tem um amplo fator na defesa para o RN, sendo que estes elementos são a maior parte da função de proteção desse primeiro leite. Essa fase de alimentação tem seu ponto máximo de nutrientes até o quinto dia pósparto, proteção essa contra microrganismos.

Considerado como a primeira vacina para o $\mathrm{RN}$, o colostro é de suma importância na alimentação, proporcionando vantagens imunológicas, psicológicas e econômicas que são reconhecidas e inquestionáveis. Os benefícios oferecidos pelo colostro são inúmeros, do ponto de vida biológico e social, logo esta prática traz vantagens para a mulher, para a criança, para a sua família e para a sociedade.

A figura do leite fraco é uma das principais causas da complementação precoce dos RN alegado pelas mães, tendo o leite de vaca sendo usado como comparação fazendo com que esta crença seja aumentada (MARQUES, 2009).

O objetivo da pesquisa foi desconstruir alguns mitos que muitas mães, em especial a da ESF estudada, sobre o colostro, em rodas de conversa durante as consultas de pré-natal no Centro de Saúde Professor Mariano de Andrade, bairro Caranã, Boa Vista, RR. Os objetivos específicos foram: (1) Constituir a Roda de Conversa como uma técnica aplicável em pesquisas de Ciências da Saúde; (2) Relatar a importância do colostro como agente imunológico presente no leite materno que atua como a primeira vacina após o nascimento da criança; (3) Apresentar os aspectos bioquímicos do colostro.

A pesquisa foi do tipo Pesquisa-Ação.

\section{COLOSTRO}

Para Issler (2008, p, 199), “colostro humano é definido como o primeiro produto da secreção láctea da nutriz, até o sétimo dia após parto, e constitui o leite que possui maior quantidade de fatores anti-infeciosos". Considerado como uma primeira vacina prevenindo contra inúmeras infecções, ajudando no desenvolvimento social, intelectual, cognitivo e neuromotor, além de contribuir para aumentar os laços efetivos entre mãe e filho (DACROCE; DAVERSA; KURSHNER, 2014).

De acordo com Issler (2008, p. 275), “o colostro, possibilita a aquisição de componentes solúveis e celulares imunologicamente competentes complexos na proteção do RN contra inúmeras doenças". Particularmente, com um número muito grande de leucócitos e de imunoglobulinas, o colostro tem um amplo fator na defesa imunitária para o RN, sendo que estes elementos são a maior parte da função protética desse primeiro leite. Essa fase de alimentação tem seu ponto máximo de nutrientes até o quinto dia pós-parto, proteção essa contra microrganismos presentes tanto no canal do parto quanto no meio externo (SANTOS; OTÁVIO; CAMILO, 2013). 
O fator energético do colostro é de mais ou menos $58 \mathrm{Kcal} / 100 \mathrm{ml}$, e tendo um volume produzido por mamada de 2 a $20 \mathrm{~mL}$, após o quinto dia começam a ocorrer mudanças na sua composição. Mudanças essas que são graduais e progressivas, chamando ao longo desse prazo de leite de transição. Passando o prazo e essas mudanças, o leite começa a ser chamado de leite maduro (Ibid., 2013).

\section{A IMPORTÂNCIA DO COLOSTRO PARA O RECÉM-NASCIDO}

Ao nascimento, o RN é transferido de um ambiente limpo e longe de agentes infecciosos e maléficos para um ambiente povoado de microrganismos. Devido à imaturidade do seu sistema imunológico, o colostro materno torna-se de essencial importância com seus fatores imunológicos e sociais. Com características essenciais a esta secreção, como sua composição química que preenche as necessidades nutricionais do $\mathrm{RN}$ (ISSLER, 2008).

De acordo com Barros et al (2009, p 103), "Na alimentação adequada, desde o início da vida, é de grande importância para a criança, pois além de ser fator fundamental para o seu crescimento e desenvolvimento, previne distúrbios nutricionais e metabólicos de difícil correção em idades posteriores".

$\mathrm{Na}$ composição do colostro existe o fator bífido, que estimula o desenvolvimento do intestino do recém-nascido para que este esteja preparado para fazer a digestão e a absorção do leite maduro, evitar a absorção de proteínas não digeridas e ainda auxiliar na evacuação do mecônio (DACROCE; DAVERSA; KURSHNER, 2014).

O preenchimento precoce de inúmeras bactérias da mãe para o neonato e o desenvolvimento de lactobacilos e bifidobactérias produtos essenciais para o $\mathrm{RN}$ constitui um fator capital para uma flora intestinal saudável. Como o $\mathrm{RN}$ é mais propenso a adquirir doenças, a amamentação e o colostro em si oferecem tudo que os fatores imunológicos do bebê precisam para proteger a mucosa intestinal, estimular a maturação epitelial e fazer com que as produções de enzimas sejam aumentadas protegendo-os na fase de lactação do colostro (SANTOS; OTÁVIO; CAMILO, 2013).

Com uma abundância de medidas protetoras para o neonato, o colostro compensa a ingenuidade do sistema imune adaptativo do RN. Uma gama muito grande de componentes ajudam para que o sistema imune inato do neonato e do leite materno fornece uma proteção rápida e continua contra amplos grupos de moléculas, sem entanto gerar memória (ODDY, 2013).

A lactose e os oligossacarídeos são os carboidratos que se encontram no leite humano. Os oligossacarídeos, na presença de peptídeos, formam um fator bífido, impedindo por ação seletiva que novas bactérias recémchegadas ao intestino e os possíveis agentes patogênicos da diarreia, como a Escherichia coli, e outras enterobactérias invadam o trato intestinal do neonato. No meio rico em 
lactose, produzirá ácido láctico e succínico, o que diminui o $\mathrm{pH}$ intestinal, tornando o local desfavorável ao crescimento de bactérias patogênicas, parasitas e fungos. A lactose também exerce fator protetor ao desenvolvimento de afecções gastrintestinais, promovendo essa colonização benéfica (PASSANHA; MANCUSO; SILVA, 2010).

A mucina está no colostro ligada com glóbulos de gordura, sendo esta, uma proteína com função de inibir a adesão bacteriana das fímbrias da Escherichia coli a mucosa, promovendo maior função de proteção gastrintestinal (Ibid., 2010).

O mau funcionamento ou até mesmo a falta desses componentes no sistema imune do RN e no leite ingerido pelo mesmo poderá permitir o desenvolvimento de inúmeras doenças causadas pela falta de nutrientes, células e anticorpos que são de essencial importância vital do neonato, que vem ao mundo com um sistema sem defesas contra microrganismos externos. O colostro e sua gama de nutrientes serão de grande importância para evitar problemas futuros.

\section{PROCESSOS DE DESMAME PRECOCE}

A figura do leite fraco é uma das principais causas da complementação precoce dos $\mathrm{RN}$ alegado pelas mães, tendo o leite de vaca sendo usado como comparação fazendo com que esta crença seja aumentada (MARQUES, 2009). A aparência aguada não só do colostro mas também do leite maduro, faz com que mães considerem um leite inferior, considerando e acreditando que não servem para atender a demanda nutricional das crianças e definindo o leite de vaca como leite forte (MARQUES, 2009)

De acordo com Oddy (2013),

Mais de quatro milhões de bebês morrem no período neonatal todos os anos, e grande parte desses óbitos ocorre em países mais pobres. Quanto maior o atraso no início do aleitamento materno, maiores as chances de mortalidade neonatal causada por infecções. O aleitamento materno na primeira hora de vida demonstrou redução nessa taxa de mortalidade neonatal elevada em $22 \%$. Durante esse período sensível, o efeito protetor do aleitamento materno fornecido no colostro pode estar relacionado a vários mecanismos, que incluem a colonização intestinal por bactérias específicas encontradas no leite materno e à capacidade de o leite materno produzir fatores imunológicos bioativos adequados para o recém-nascido. A Iniciativa do Hospital Amigo da Criança (IHAC), por meio da Organização Mundial de Saúde (OMS), recomenda colocar os bebês em contato com a pele de suas mães imediatamente após o nascimento por, no mínimo, uma hora, e ajudar as mães a reconhecer quando seus bebês já estão prontos para a amamentação.

Representando umas das experiências nutricionais mais precoces do $\mathrm{RN}$, o aleitamento materno é de suma importância, pois não há em nenhum outro leite industrializado ou alimento capaz de oferecer ao neonato todos os ingredientes do leite materno e consequentemente o colostro. $\mathrm{O}$ leite materno apresenta uma composição específica que se ajusta à necessidade nutricional do bebê e sendo compatível com as necessidades metabólicas e fisiológica do mesmo não apresentando nem ônus ao orçamento familiar e tendo uma interação social junto a mãe e o bebê estreitando seus laços de afeto. Nos últimos 30 anos vêm aumentando a duração e a frequência da amamentação desde as primeiras horas de 
vida. Entretanto, apesar do consenso acerca das inúmeras vantagens do aleitamento maternos, importância do colostro nas mobilizações mundiais, a prática de desmame ainda é comum em todo o mundo fazendo com que futuras crianças sofram com problemas que poderiam ser evitados amamentando. (PASSANHA; MANCUSO; SILVA, 2010).

Problemas presentes e futuros poderiam ser evitados com o simples ato de amamentar, problemas gastrintestinais, respiratórios entre outros. O falso leite fraco (ideia das mães entrevistadas) faz com que a cada dia, se coloque alimentos, leite industrializado e outros no lugar do colostro tirando a possibilidade do amadurecimento completo do sistema imune e da flora intestinal do RN, forçando-os a passar por situações que não deveriam acontecer.

Implementação de políticas e rotinas próaleitamento materno nas primeiras horas de vida podem mudar o perfil neonatal pois o aleitamento materno e o contato com o colostro é o melhor custo benefício para a redução das infecções nos $\mathrm{RN}$.

\section{DIFERENÇA DO COLOSTRO DE} RECÉM-NASCIDOS A TERMO E PRÉ-

\section{TERMO}

De acordo com Oddy (2013), os mecanismos biologicamente plausíveis por meio dos quais o aleitamento materno poderá afetar a mortalidade neonatal foram propostos com a ideia de que o leite materno muda segundo a necessidade dos RN para proporcionar proteção imunológica passiva.

Para Brasil, (2009), “o leite de mães de recém-nascidos prematuros é diferente do de mães de bebês a termo". Observe o Quadro1

Quadro 1 -Composição do Colostro de crianças a termo e pré-termo

\begin{tabular}{|lll|}
\hline NUTRIENTES & Colostro (3-5 dias) & \\
\cline { 2 - 2 } & A termo & Pré-termo \\
\hline Calorias $(\mathrm{kcal} / \mathrm{dL})$ & 48 & 58 \\
\hline Lipidios $(\mathrm{g} / \mathrm{dL})$ & 1,8 & 3,0 \\
\hline Proteinas $(\mathrm{g} / \mathrm{dL})$ & 1,9 & 2,1 \\
\hline Lactose $(\mathrm{g} / \mathrm{g} \mathrm{L})$ & 5,1 & 5,0 \\
\hline
\end{tabular}

Fonte: Adaptado de Brasil (2009).

O estado nutricional da mãe e a idade cronológica das mesmas não influenciam de forma significante as concentrações de nutrientes, imunoglobulinas, células, albuminas, proteínas totais, $\operatorname{IgA} \mathrm{e}$ IgGpresentes no colostro. Mesmo em condições variadas de dieta materna a concentração de oligoelementos no leite é regulada pela própria glândula mamária por meios específicos. Com a concentração dos fatores de proteção no colostro de mães de bebês pré-termo, sua composição apresenta algumas diferenças em comparação com colostro de mães de $\mathrm{RN}$ a termo, pois o próprio organismo da mãe reconhece a necessidades do neonato por haver maior risco de desenvolver complicações no trato gastrintestinal e respiratórios desses pequenos. As propriedades necessárias fisiológicas e imunológicas, nutricionais e anti-infeciosas de RNpré-termo são alcançadas pelo colostro, as necessidades do tubo intestinal imaturo precisam de uma 
maior quantidade de $\operatorname{Ig} \mathrm{A}$, lisozima e lactorrafina essenciais para maturação do intestino do bebê pré-termo (PASSANHA; MANCUSO; SILVA, 2010).

O colostro tem tudo que o bebê precisa até nas horas mais incertas. Quando o RN nasce antes do tempo as próprias glândulas mamárias da mãe colocam as necessidades fundamentais desse bebê para que o mais rápido possível ocorra maturação intestinal, respiratório e imunológica do mesmo (DACROCE; DAVERSA; KURSHNER, 2014). A diferença entre o colostro do neonato a termo e pré-termo é evidente mostrando que nem sempre as coisas podem ser iguais para chegar ao mesmo objetivo, a saúde da criança (BRASIL, 2009).

\section{PROTEÇÃO DO COLOSTRO}

A partir do nascimento do bebê diversas linhagens de Escherichia coli colonizam o intestino humano, fazendo parte da sua flora intestinal. Mas por um lado algumas dessas linhagens podem chegar a causar doenças intestinais graves, por ainda o $\mathrm{RN}$ não ter os mecanismos de defesa imunológicos antes ser amamentado. Sua imaturidade do epitélio intestinal, a baixa acidez gástrica e a menor atividade de enzimas circulantes no bebê não constitui uma barreira muito eficiente contra a entrada de microrganismos. Crianças em lactação desde o primeiro dia pós parto onde o colostro tem uma gama maior de nutrientes apresentam a curto, médio e longo prazo uma flora intestinal benéfica, tendo uma menor quantidade de Clostridium dificile e Escherichia e maior de bifidobactérias que beneficiam a saúde humana (PASSANHA; MANCUSO; SILVA, 2010).

Para Issler (2008, p. 275)

No leite humano encontram-se diversos fatores de proteção com ação antiinfeciosas, como enzimas, citocinas, componentes do sistema complemento, células, oligossacarídeos, nucleotídeos, lipídios e hormônios, que interagem entre si e com as mucosas do tratos digestivo e respiratório do $\mathrm{RN}$, conferindo além da imunidade passiva, estímulo ao desenvolvimento e à maturação do seu sistema imunológico.

O colostro e o leite maduro apresentam fatores antimicrobianos com algumas características comuns, protegendo as superfícies das mucosas e eliminando bactérias, com a degradação e a resistência das enzimas digestivas e não iniciando reações inflamatórias. A lisozima e a lactorrafina estão entre as principais enzimas presentes no colostro. A lisozima age como uma interação bactericida, fazendo com que a integridade da parede externa das bactérias seja destruída, ou potencializa as ações de outros fatores antimicrobianos presentes no colostro. A lactoferrina corresponde a $26 \%$ do conteúdo protéico do colostro e apresenta uma função bacteriostática na mucosa intestinal do $\mathrm{RN}$, por meio do sequestro do ferro presente no sistema digestivo da criança, impedindo o desenvolvimento de diversos patógenos (ISSLER, 2008).

A principal imunoglobulina encontrada no colostro é a IgA, está presente no intestinos de RN alimentados com leite humano, age impedindo a aderência de vírus e bactérias nas 
mucosas intestinais impedido assim uma invasão se ligando a microrganismos e macromoléculas, inibindo a interação entre bactérias e células epiteliais, neutralizando as toxinas e os fatores de virulências prevenindo o contato de patógenos com o epitélio, dessa forma a IgA protege a mucosa contra diarreias, pois forma um revestimento protetor nas superfícies da mucosa do lactente. O IgA pode ser encontrado ileso em fezes do RN, resistindo ao longo de todo o trato gastrintestinal, são encontrados ainda com a mesma reatividade contras microrganismos que apresentavam quando no colostro, com sua atividade anti-infecciosa ainda preservada, promovendo maior resistência de enzimas proteolíticas, abundantes nas secreções mucosas. Com o decorrer da lactação começa a ocorrer um declínio do anticorpo IgA, no decorrer desse declínio as atividades biológicas de inibição bacteriana continuam inalteradas, fazendo com que crianças permaneçam protegidas contra gastrenterites durante todo o período de lactação do mesmo. As diarreias são mais frequentes após encerramento do aleitamento independentemente da idade que ocorra (PASSANHA; MANCUSO; SILVA, 2010).

O grande número de leucócitos viáveis no colostro, como os fagócitos polimorfonucleares e mononucleares, incluindo um grande número de macrófagos é ainda desconhecidaa respeito de suas possíveis funções, são células derivadas do sangue periférico, e chegam à glândula mamária por moléculas de adesão após estimulo hormonal no período em que o colostro está entre o final da gestação e o início da lactação. Atravessando o epitélio, são liberadas na secreção do leite. Essa concentração de leucócitos viáveis é que diferencia o colostro e o leite humano da maioria das outras secreções, tendo uma agrupamento maior no colostro e vai diminuindo durante o primeiro mês de lactação à medida em que vai aparecendo o leite maduro, de forma que esse leite só contém $2 \%$ da concentração dessas células (ISSLER, 2008).

Para Baldan, Farias e Bácaro (2013, p. 05)

Concentração de leucócitos, macrófagos e linfócitos no colostro é de $5 \mathrm{~g} / \mathrm{L}$, menor no leite maduro que é de 0,5 a $1,5 \mathrm{~g} / \mathrm{L}$ (mas a quantidade ingerida é grande porque a criança ingere maior volume de leite). Um adulto de $65 \mathrm{~kg}$ produz cerca de 2,5g/dia, os leucócitos, macrófagos e linfócitos têm a particularidade de estar ativos, prontos a exercer a sua ação caso encontrem bactérias.

Os discursos que trazem as propriedades benéficas do colostro revelaram que esse leite apresenta altas concentrações de anticorpos com a predominância da IgA. Essas imunoglobulinas, durante $\mathrm{o}$ aleitamento praticado pela puérpera, começam a integrar a isenta e vulnerável mucosa gastrointestinal do neonato, impedindo, continuamente, a aderência e colonização da mucosa do trato digestivo infantil. Outras células presentes no leite materno e que conferem a este uma característica protetora são os leucócitos (macrófagos, neutrófilos) que fagocitam microrganismos patogênicos, fazendo com que o neonato fique protegido de doenças que 
são evitadas pelo simples ato de amamentar desde o primeiro dia de vida (SANTOS; OTÁVIO; CAMILO, 2009) .

\section{METODOLOGIA}

Quanto ao procedimentos técnicos, a pesquisa foi do tipo pesquisa-ação. Segundo Ludwing, (2012, p. 60-61), "pode-se conceituar esta forma de estudo como uma atividade cooperativa entre pesquisador e pesquisado com vistas a solucionar problemas coletivos, algumas peculiaridades é a predominância de um forte envolvimento dos interessados no estudo e a intenção declarada de intervir na realidade para mudá-la". Este trabalho foi desenvolvido no Centro de Saúde Prof $^{\circ}$ Mariano de Andrade localizada na área de atuação da equipe daquela ESF (Estratégia Saúde da Família), com o objetivo de se passar informações a respeito da amamentação na primeira semana de vida tirando dúvidas e quebrando mitos a respeito do colostro e mostrando o que na realidade é este rico leite, junto a gestantes que fazem pré-natal naquela unidade.

\section{ANÁLISE E DISCUSSÃO DOS RESULTADOS}

As informações que foram recolhidas a partir dos questionários na roda de conversa foram de grande ajuda para construção de uma base de dados, que serviu de apoio às análises dos respostas e dúvidas obtidas.No primeiro bloco foi procurado conhecer a gestante: idade, nível de escolaridade, idade gestacional, a quantidade de filhos, situação conjugal e se ela já apresentou algum problema em relação àamamentação.No Bloco 2 se procurou saber a respeito do colostro: se elas conheciam esse líquido e se já alimentaram seu filho com esse leite.O bloco 3 quis verificar o conhecimento das gestantes no que tange aos mitos e verdades sobre o colostro, com perguntas de verdades ou mentiras a respeito da amamentação e do colostro.O bloco 4 se concentrou em saber o conhecimento das gestantes sobre os nutrientes do colostro e se as grávidas já tiveram algum tipo de conhecimento prévio a respeito da amamentação.

Logo após o questionário, foi feita no local uma roda de conversa, na qual as gestantes ouviram sobre o colostro e sobre a amamentação, para que pudessem entender melhor sobre o assunto e em alguns casos conhecer sobre o mesmo.Nessa roda de conversa, foram abordados vários temas. Muitas chegavam a fugir do assunto, mas logo dávamos um norteamento a conversa $\mathrm{e}$ continuávamos a respeito do colostro. Foi entendido que as mães e futuras mães até conhecem o colostro mas não davam tanta importância ao mesmo, achando que se tratava de um leite comum. Foram abordados os nutrientes que existiam, a importância do colostro, o que ele poderia evitar em problemas tantos no presente quanto futuros, tempo que esse rico leite circula nas glândulas mamárias da mãe e o mais importante: o afeto mãe e filho. 
No gráfico 1, o conhecimento das gestantes no que concerne aos mitos e verdades sobre o colostro.

Gráfico 1 - Mitos e Verdades sobre o colostro

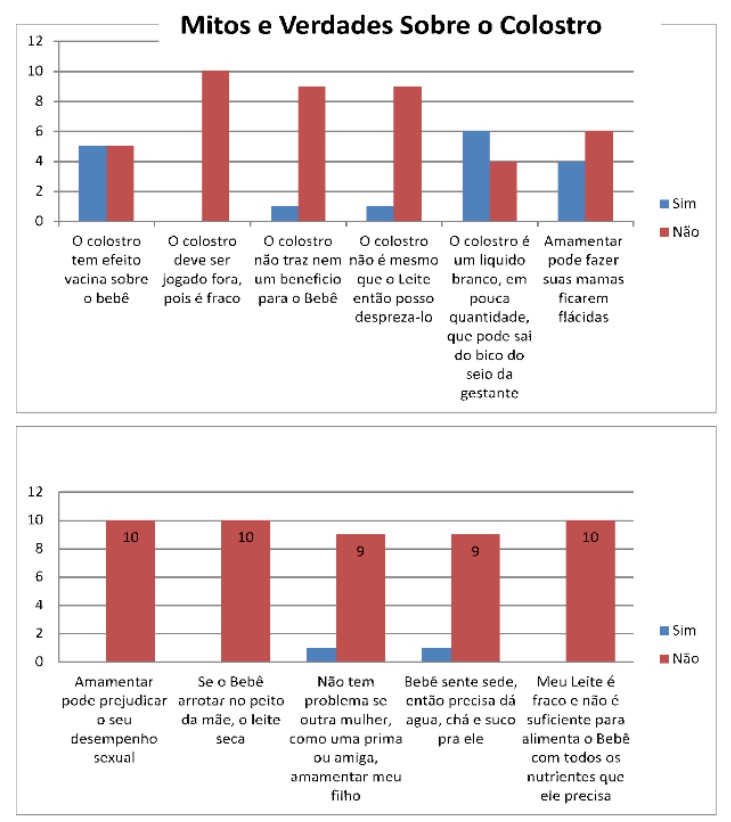

Fonte: Pesquisa de Campo (2014).

Apesar de vivermos na chamada Sociedade da Informação, muitas mães ainda pensam que o colostro é fraco e deve ser jogado fora, descartado. Foi constatado que a maioria das clientes em consulta de pré-natal não conhecem o colostro e as que conhecem normalmente não davam importância. Em relação à amamentação em si, elas estão mais bem informadas: todas responderam que amamentar não prejudica o desempenho sexual, que se o bebê arrotar no peito o leite não seca e que seu leite era suficiente para alimentar o bebê (com todos os nutrientes necessários).

\section{CONSIDERAÇÕES}

Em relação ao objetivo de constituir a Roda de Conversa como uma técnica aplicável em pesquisas de Ciências da Saúde, constatou-se que é possível sim, pois, inclusive as mesmas conversaram não só com o pesquisador mas também entre elas e com a profissional de enfermagem do centro de saúde em questão, quebrando mitos e conhecendo a realidade deste rico leite. Observou-se que as mesmas se sentiram à vontade, uma vez que suas dúvidas foram completamente sanadas.

O objetivo de se relatar a importância do colostro, como agente imunológico presente no leite materno atuando como uma primeira vacina, após o nascimento da criança foi bem esclarecido, sendo articulado na roda conversa com uma linguagem simples e dinâmica para o entendimento das gestantes a importância que esse rico leite traz a saúde do recémnascido, tendo todos os nutrientes que o recém-nascido precisa, incluindo-se também as importâncias sociais e econômicas que o colostro engloba.

A apresentação dos aspectos biológicos do colostro foram um fator de maior problemática, o entendimento das mães não se embasava em palavras técnicas e as ações desses fatores no organismo, sendo passado de forma sucinta e em escala mais ampla mostrando a cada gestante o que se encontra na composição do colostro e os benefícios do mesmo ao recém-nascido.

Portanto, vale a pena ressaltar a necessidade de uma política de sensibilização começando 
pela base da pirâmide, logo no pré-natal, sobre a amamentação em especial o colostro, considerado como o liquido mais importante de toda uma vida, e que com a falta de informação faz com que mães o desprezem e

\section{REFERENCIAS}

BALDAN, M.A; FARIAS, V. P; BÁCARO, S. D. Comparativo entre aleitamento materno exclusivo e outros tipos de leite no desenvolvimento imunológico de crianças de 0 a 12 meses.Revista Funec Científica -

Nutrição, v.1, n.1, jul-dez. 2013.

BARROS, V. O. et al. Aleitamento materno e fatores associados ao desmame precoce em crianças atendidas no programa de saúde da familia. Nutrire: rev. Soc. ras. Alim. Nutr.= J. Brazilian Soc. Food Nutr., São Paulo, SP, v. 34, n. 2, p. 103, ago. 2009.

BRASIL. Saúde Da Criança: Nutrição Infantil Aleitamento Materno e Alimentação Complementar. Brasília - DF: Ministério da Saúde, 2009

DACROCE, M; DAVERSA, C; KURSHNER, C. F. Os Benefícios do aleitamento materno ao (rn) prematuro. FIGESC, v. 3, n.3. 2014. Disponível em: <http://seerfuture.com.br/index.php/FIGESC/ article/view/18>. Acesso em 15 out. 2014.

ISSLER, Hugo.O Aleitamento Materno no

Contexto Atual: Políticas, Prática e Bases Científicas. São Paulo: Sarvier, 2008.

LUDWING, A. C. W.Fundamentos e prática de metodologia científica. 2.ed. Petrópolis: Vozes, 2012.

ODDY, W. H. Aleitamento Materno na primeira hora de vida protege contra mortalidade neonatal. Jornal de Pediatria, Rio de Janeiro, mar. 2013. (sem paginação).

PASSANHA, A; MANCUSO, A. M. C; SILVA, M. E. M. P; Elementos protetores do o troquem por alimentos que não exerce a mesma função de proteção intestinal e metabólica do bebê logo nas primeiras horas de nascido.

leite materno na prevenção de doenças gastrintestinais e respiratórias. Revista brasileira de crescimento e desenvolvimento humano São Paulo, SP, p Sem paginação, Agosto - 2010

SANTOS, A.B; OTÁVIO, I. C. S. Luz; CAMILO, J. C. A importância do colostro e do aleitamento materno para o desenvolvimento/crescimento dos recémnascidos. Brasília: [s.n.], 2013. 